Accepted refereed manuscript of:

Asimakopoulos S \& Karavias Y (2016) The impact of government size on economic growth: a threshold analysis, Economics Letters, 139, pp. 65-68.

DOI: $\underline{10.1016 / \text { j.econlet.2015.12.010 }}$

(C) 2016, Elsevier. Licensed under the Creative Commons AttributionNonCommercial-NoDerivatives 4.0 International

http://creativecommons.org/licenses/by-nc-nd/4.0/ 


\title{
The impact of government size on economic growth: a threshold analysis
}

\author{
Stylianos Asimakopoulos \\ University of Stirling
}

\author{
Yiannis Karavias* \\ University of Birmingham
}

\begin{abstract}
We examine the nature of the relationship between government size and economic growth and identify the optimal level of government size using a large dataset through a novel and very general non-linear panel Generalized Method of Moments approach. We show that this relationship is statistically significant above and below the optimal level, even after splitting our sample to developed and developing countries. Finally, we find an asymmetric impact of government size on economic growth in both developed and developing countries around the estimated threshold.
\end{abstract}

Keywords: government size, economic growth, dynamic threshold estimation JEL Classification: E62, C23, O11, O50

${ }^{*}$ Corresponding author: i.karavias@bham.ac.uk

Acknowledgements: We are grateful to an anonymous referee for helpful suggestions. We also benefited from comments by Filipa Fernandes, Maria Grydaki, Joan Paredes, Lazaros Symeonidis, Elias Tzavalis and Thomas Warmedinger. The views expressed here are entirely our own. 


\section{Introduction}

The impact of government size on economic growth has been the focal point of academic research for many years (i.e. Barro (1990), Karras (1997), Gunalp and Dincer (2010) among others). Over the past decade, and especially following the recent European sovereign debt crisis, the level of government spending has been at the centre of many political debates. For instance, one of the primary targets of the Euro Plus Pact in 2011 is the sustainability of public finances within the European Union.

An oversized government sector may have negative spillover effects to the economy due to financing of government spending via increasing taxes, borrowing and/or printing money. On the contrary, if government spending is very small, or even zero, the economic growth is very limited due to difficulties in the provision of public goods. Therefore, the optimal level of government spending which maximizes growth is an issue of paramount importance.

The empirical literature is yet inconclusive. Several papers, using linear approaches, find that government spending and growth are negatively related (e.g. Dar and AmirKhalkhali (2002) and Guseh (2007)), whereas other studies find a positive relationship (e.g. Bose et al. (2007) and Romero-Ávila and Strauch (2008)).

The majority of existing literature supports an inverted "U-shaped" curve relationship between government spending and economic growth, also known as the BARS curve after Barro (1990), Armey (1995), Rahn and Fox (1996) and Scully (1995). In other words, the increase of government spending is beneficial up to a certain threshold but beyond that level the impact on growth is negative. Studies that empirically test the BARS curve include: Karras (1997), Chen and Lee (2005), Chiou-Wei et al. (2010), Gunalp and Dincer (2010) and Altunc and Aydin (2013). ${ }^{1}$

In order to establish the optimal level of government spending, a rich panel of countries should be employed. Most important, there is a prevailing issue of endogeneity, which has not been addressed in the literature, since higher growth over a time period may incite greater government spending through the channel of higher returns from taxation.

In this paper we uncover the non-linear relationship between government size and economic growth and identify the optimal government expenditure through the novel non-linear panel GMM approach of Seo and Shin (2014) which allows for a threshold effect with endogenous regressors and threshold

\footnotetext{
${ }^{1}$ We would like to mention here that throughout the paper we follow the related literature and we define as government spending and size the general government final consumption expenditure which does not include government investment.
} 
variables. Using a large dataset of 129 countries $^{2}$, we establish a robust and statistically significant non-linear relationship between government spending and economic growth. Furthermore, we show that this impact remains valid even if we split the sample to developed and developing countries, with asymmetric effects on the two groups.

The remainder of the paper is organised as follows. Section 2 presents the model. Section 3 analyses the results and Section 4 presents the conclusions.

\section{Model}

Following the endogenous growth literature (i.e. Barro (1990) and Karras (1997)) we use as dependent variable the growth rate of GDP per capita and as explanatory variables the following: i) the general government final consumption expenditure as a share of output; ii) the inflation rate as the percentage change of CPI; iii) the gross capital formation to capture the share of investment to output; iv) openness to trade; and v) population growth. We use data on 129 countries from the World Development Indicators (WDI) for the period 1980-2009 using non-overlapping 5-year periods and averaging the data per variable and country within that period. We then perform a dynamic panel threshold estimation to estimate the optimal level of government spending for the average country in our sample. The model we use is:

$$
\begin{aligned}
\text { GROWTH }_{i, t}= & a_{i}+\phi G R O W T H_{i, t-1}+\beta_{1} G O V_{i, t} I\left(G O V_{i, t} \leq \gamma\right) \\
& +\beta_{2} G O V_{i, t} I\left(G O V_{i, t}>\gamma\right)+\delta X_{i, t}+\nu_{t}+\varepsilon_{i, t}
\end{aligned}
$$

where $a_{i}$ is the individual effect for each country which captures individual heterogeneity, $\nu_{t}$ is the common time effect which captures comovement of the series due to external shocks and $\varepsilon_{i t}$ is the remainder error term. $G O V$ is the government final consumption expenditure as a share of GDP and serves as the threshold variable where the threshold is given by the parameter $\gamma$. $I(\cdot)$ is the indicator function which takes the value 1 when the condition in the parenthesis is satisfied and 0 otherwise. Vector $X_{i, t}$ contains inflation, capital formation, openness to trade and population growth variables.

The model commonly used in the literature (e.g. Islam (1995), Levine et al. (2000)) is the following: $y_{i, t}=\phi y_{i, t-1}+\delta x_{i, t}+a_{i}+\varepsilon_{i, t}$, or, augmented with threshold terms: $y_{i, t}=\phi y_{i, t-1}+\beta_{1} z_{i, t} I\left(q_{i, t} \leq \gamma\right)+\beta_{2} z_{i, t} I\left(q_{i, t}>\gamma\right)+\delta x_{i, t}+$ $a_{i}+\varepsilon_{i, t}$ where $y=\ln (G D P /$ capita $)$. We noticed that $\ln (G D P /$ capita $)$ is highly persistent so we tested all variables for nonstationarity using panel

\footnotetext{
${ }^{2}$ We use all the available countries in the World Bank dataset with observations for all the variables we consider for the period under consideration.
} 
unit root tests for small time dimension (Harris and Tzavalis (1999)). We find that $\ln (G D P /$ capita $)$ is the only nonstationary variable and therefore it enters our model in first differences, i.e. $\Delta y_{i, t}=G R O W T H_{i, t}$ in model (1).

Rewriting the linear literature model as: $\Delta y_{i, t}=(\phi-1) y_{i, t-1}+\delta x_{i, t}+$ $\beta_{1} z_{i, t} I\left(q_{i, t} \leq \gamma\right)+\beta_{2} z_{i, t} I\left(q_{i, t}>\gamma\right)+a_{i}+\varepsilon_{i, t}$ we can compare it with our model that has $\Delta y_{i, t-1}$ instead of $y_{i, t-1}$ as the explanatory variable due to nonstationarity: $\Delta y_{i, t}=\phi \Delta y_{i, t-1}+\beta_{1} z_{i, t} I\left(q_{i, t} \leq \gamma\right)+\beta_{2} z_{i, t} I\left(q_{i, t}>\gamma\right)+$ $\delta x_{i, t}+c_{i}+\xi_{i, t}$. Thus, the interpretation of $\beta$ and $\delta$ is the same in both models, but the interpretation of $\phi$ changes. ${ }^{3}$ We should also note that the two models have different individual effects and error terms but this does not lead to inconsistent estimators because the correct instruments are used in each case. ${ }^{4}$

We estimate model (1) using the novel GMM method of Seo and Shin (2014) which allows for endogenous regressors and threshold variables and uses Arellano and Bond (1991) type instruments. The method proceeds in two steps: i) for a selected parameter value of $\gamma$, estimates of $\theta=\left(\phi, \beta_{1}, \beta_{2}, \delta\right)$ are obtained by Arellano-Bond GMM; ii) step (i) is repeated for $\gamma^{\prime} s$ belonging in a strict subset of the support of $G O V$, resulting in a different $\hat{\theta}_{G M M}$ for each selected $\gamma$. The $\gamma$ which minimizes the GMM-type objective function and its corresponding $\hat{\theta}_{G M M}$ are the optimal estimated parameters.

Compared with other methods in the threshold literature, namely the static method of Hansen (1999) (used by Christie (2014)) and the GMM method of Kremer et al. (2013), the applied one here has the advantage that it allows for endogenous regressors and endogenous threshold variables. This is empirically relevant because higher growth over a period of time may incite greater government spending through the channel of higher returns from taxation. We estimate the model using five year averaged data and time dummies to abstract from business cycle influences (see Levine et al. $(2000)) .^{5}$

\footnotetext{
${ }^{3}$ The parameter $\phi$ captures the speed of convergence and it is not the focus of our paper. The focus of our paper is the parameters $\beta$ and $\delta$ that are not affected by this transformation.

${ }^{4}$ For the literature model the levels and differences of $y_{i, t-1}$ are used as instruments, while for our model the levels and differences of $\Delta y_{i, t-1}$ form the instruments.

${ }^{5}$ In all cases the full set of collapsed instruments was used to improve the small sample properties, see e.g. Roodman (2009). The Windmeijer small sample correction was not implemented as it is unclear if it extends to non-linear GMM as in this case. Time dummies are used only in the full sample regression because in the subsamples examined the number of countries drops considerably and extra variables lead to disproportionate number of instruments. Finally, as Table 1 indicates below, the parameter $\phi$ is very far from the value of 1 and so there is no weak instrumentation problem. The results with the System GMM estimator are qualitatively similar and thus are not reported here but
} 


\section{Results}

Table 1 presents the results from the estimation of model (1). The first column shows the results for the full sample, whereas columns two and three present the results for developing and developed countries respectively. ${ }^{6}$

Regarding the full sample, we find that the optimal threshold level of government size is $18.04 \%$. This falls within the range reported in the related literature. For example, Karras (1997), in a sample of 20 European countries, finds that the optimal level of government spending is equal to $16 \%$, whereas Gunalp and Dincer (2010), in a sample of 20 transition countries, reports a threshold of $17.3 \%$. In different studies on individual countries, Chen and Lee (2005), Chiou-Wei et al. (2010) and Altunc and Aydin (2013) report a threshold estimation within the range of $11-25 \% .^{7}$

Besides the estimation of the optimal level of government spending we determine its non-linear impact on economic growth when it is above and below that level. In other words, we assess empirically the validity of BARS curve. We find strong evidence of the existence of an inverted "U-shaped" relationship between government size and economic growth. We are the first to uncover a statistically significant relationship between government spending and economic growth for both above and below the optimal level of government spending. ${ }^{8}$

In particular, under the full sample, when the government size of the average country is below the threshold, a $1 \%$ increase in government spending, as a share of GDP, will enhance economic growth by $0.99 \%$. However, if the average country is above the threshold then a $1 \%$ increase in government size will decrease growth by $0.65 \%$. Therefore, the impact of government spending on growth is larger quantitatively when it is below the estimated threshold.

The above result remains valid even if we split our sample to developed and developing countries with estimated thresholds equal to $17.96 \%$ and

are available upon request.

${ }^{6}$ The developed countries are those listed as high income countries and the rest of the countries are assumed to be developing, following the classification of the World Bank.

${ }^{7}$ Note that the relevant estimated threshold of government size refers to the level of general government final consumption expenditure which does not include government investment. This approach is common in the related literature due to data availability issues.

${ }^{8} \mathrm{We}$ have also estimated our main regression with the inclusion of initial GDP as a robustness check and the results do not change significantly. The results are available upon request. However, we should note here that the use of initial GDP in our dynamic panel model is redundant because convergence is captured by the model dynamics, see. e.g. Islam (1995). 
$19.12 \%$ respectively. ${ }^{9}$ Gray et al. (2007) has shown that larger governments tend to allocate a bigger share of their spending on unproductive sources compared to smaller countries. As a result, taking into account that government spending is mostly financed via taxation, a lower threshold estimation should be optimal for the developed countries.

In our sample the average government spending for the developing countries is $14.83 \%$, whereas for the developed countries it is $17.88 \%$. This indicates that the majority of the developing countries are still on the upward slopping part of the BARS curve and they can benefit from an increase in their government spending. On the other hand, the government size of the average developed country is very close to their optimal level.

Furthermore, we find that for the developing countries the negative effect of a larger than optimal government size is more significant quantitatively than the positive effect from a government size below optimal. In addition, developed countries have stronger positive effects when government size increases when it is below optimal, compared to the negative effects when it is above the estimated threshold. As a result, there is an asymmetric impact of government size on economic growth in developed and developing countries around the estimated threshold. This result may be stemmed from the fact that the developed countries have better government institutions that are able to exploit all the benefits from the positive effects of higher government expenditure and mitigate its negative effects. ${ }^{10}$

\footnotetext{
${ }^{9}$ We have also performed the same analysis for OECD countries and we found very similar results with those for developed countries.

${ }^{10}$ However, note that the better government institutions do not lead to higher threshold effects possibly due to the argument of Gray et al. (2007) mentioned earlier. We would like to thank an anonymous referee for suggesting this possible interpretation of the result.
} 
Table 1: Results of non-linear dynamic threshold estimations

\begin{tabular}{llll}
\hline \hline Sample & Full & Developing & Developed \\
\hline Threshold & $\begin{array}{l}18.0387 \\
(28.2371)^{* * *}\end{array}$ & $\begin{array}{l}19.1246 \\
(50.66)^{* * *}\end{array}$ & $\begin{array}{l}17.9647 \\
(55.3826)^{* * *}\end{array}$ \\
\hline Government size & & & \\
$\hat{\beta}_{1}$ & 0.9948 & 0.272 & 1.048 \\
& $(4.0155)^{* * *}$ & $(2.0211)^{* *}$ & $(4.7456)^{* * *}$ \\
$\hat{\beta}_{2}$ & -0.6476 & -0.715 & -0.5975 \\
& $(-3.6051)^{* * *}$ & $(-4.0335)^{* * *}$ & $(-5.2383)^{* * *}$ \\
\hline Covariates & & & \\
Lagged Growth & 0.1373 & -0.0036 & 0.0661 \\
& $(1.8472)^{*}$ & $(-0.0321)$ & $(1.498)$ \\
Capital Formation & 0.1604 & 0.0211 & 0.2536 \\
& $(2.5523)^{* *}$ & $(0.1757)$ & $(6.4925)^{* * *}$ \\
Inflation & 0.0007 & 0.0002 & 0.0725 \\
& $(0.561)$ & $(0.1343)$ & $(0.9555)$ \\
Openness & 0.0269 & 0.1035 & 0.0128 \\
& $(0.8882)$ & $(4.688)^{* * *}$ & $(0.7566)$ \\
Population & 0.1891 & 0.6356 & -0.4027 \\
& $(0.2187)$ & $(0.854)$ & $(-0.644)$ \\
\hline Quarter effects & Yes & No & No \\
Observations & 774 & 516 & 258 \\
N & 129 & 86 & 43 \\
\hline Note: t-statistics in the parentheses. $* * * \mathrm{p}<0.01, * *: \mathrm{p}<0.05, *: \mathrm{p}<0.1$
\end{tabular}

Regarding the remaining variables we find that capital formation is positive and statistically significant for the full sample and the developed countries. The openness to trade is statistically significant only for the developing countries. Lagged growth is weakly significant for the full sample with a small positive coefficient. Finally, the coefficient of inflation is close to zero and insignificant; and population growth doesn't have any significant effect on growth either, as in the related literature. ${ }^{11}$

\footnotetext{
${ }^{11}$ Note that the insignificance of some of the growth determinants maybe due to possible non-linear effects on growth instead of the linear assumed in our analysis. When allowing for non-linear effects in both government and inflation, with government spending still being the threshold variable, we find evidence of non-linearities, as in Kremer et al. (2013). The results are available upon request. A full analysis on the subject is left for future research.
} 


\section{Conclusions}

We assessed the non-linear relationship between government size and economic growth under a large panel dataset using a dynamic panel threshold model which allows for non-linear threshold effect with endogenous regressors and threshold variables.

The empirical results verified the theoretical BARS curve. We found that the optimal level of government size that maximises economic growth is $18.04 \%$ for the full sample; $19.12 \%$ for developing and $17.96 \%$ for developed countries.

We were able to show that the inverted "U-shaped" non-linear relationship between government spending and economic growth is statistically significant around the optimal level, the upward and downward slopping part of the curve. We concluded that the results remained valid and robust under a split of our sample to developed and developing countries. Finally, we found that the effect of government spending on economic growth is asymmetric to developed and developing countries when it is above and below the optimal level.

\section{References}

[1] Altunc, O. F. and Aydın, C, 2013. The relationship between optimal size of government and economic growth: Empirical evidence from Turkey, Romania and Bulgaria, Procedia - Social and Behavioral Sciences, 92, $66-75$.

[2] Arellano, M. and Bond, S., 1991. Some Tests of Specification for Panel Data: Monte Carlo Evidence and an Application to Employment Equations. The Review of Economic Studies, 58(2), 277-297.

[3] Armay R., 1995. The Freedom Revolution, Regnery Publishing Co., Washington, D.C.

[4] Barro, R. J., 1990. Government spending in a simple model of endogenous growth, Journal of Political Economy, 98, 103-126.

[5] Bose, N., Haque, M. E. and Osborn, D. R., 2007. Public expenditure and economic growth: A disaggregated analysis for developing countries. The Manchester School, 75(5), 533-556. 
[6] Chen, S.T., and Lee, C.C., 2005. Government size and economic growth in Taiwan: A threshold regression approach, Journal of Policy Modeling, 27(9), 1051-1066.

[7] Chiou-Wei, S. Z., Zhu, Z. and Kuo, Y. H., 2010. Government size and economic growth: an application of the smooth transition regression model, Applied Economics Letters 17(14), 1405-1415.

[8] Christie, T. (2014). The effect of government spending on economic growth: Testing the non-linear hypothesis. Bulletin of Economic Research, 66(2), 183-204.

[9] Dar, A. A. and AmhirKhalkhali, S., 2002. Government size, factor accumulation, and economic growth: evidence from OECD countries. Journal of Policy Modeling, 24, 679-692.

[10] Gray, C., Lane, T. and Varoudakis, A., 2007. Fiscal Policy and Growth in ECA: Lessons for Eastern Europe and Central Asia. Washington DC: The World Bank.

[11] Gunlap, B. and Dincer, O., 2010. The optimal government size in transition countries. Progress in economics research, 15, 153-169.

[12] Guseh, J., 2007. Government size and economic growth in developing countries: A political-economy framework. Journal of Macroeconomics, 19(1), 175-192.

[13] Hansen, B. E., 1999. Threshold effects in non-dynamic panels: estimation, testing, and inference. Journal of Econometrics, 93, 345-368.

[14] Harris, Richard D. F., and Elias Tzavalis. 1999. "Inference for Unit Roots in Dynamic Panels where the Time Dimension is Fixed," Journal of Econometrics 91: 201-226.

[15] Islam, N., 1995. Growth empirics: A panel data approach. The Quarterly Journal of Economics, 110 (4), 1127-1170.

[16] Karras, G., 1997. On the Optimal Government Size in Europe: Theory and Empirical Evidence. The Manchester School of Economic \& Social Studies, 65 (3), 280-94.

[17] Kremer, S., Bick, A. and Nautz, D., 2013. Inflation and growth: new evidence from a dynamic panel threshold analysis. Empirical Economics 44 (2), 861-878. 
[18] Levine, R., Loayza, N. and Beck, T., 2000. Financial intermediation and growth: Causality and causes. Journal of Monetary Economics, 46, 31-77.

[19] Rahn R. and Fox H., 1996. What is the optimum size of government?, Vernon K. Krieble Foundation.

[20] Romero-Ávila, D. and Strauch, R., 2008. Public finances and long-term growth in Europe: Evidence from a panel data analysis, European Journal of Political Economy 24(1), 172-191.

[21] Roodman, D., 2009. A Note on the theme of too many instruments. Oxford Bulletin of Economics and Statistics 71(1):135-158.

[22] Scully, G.W., 1995. The "growth tax" in the United States, Public Choice, 85, 71-80.

[23] Seo, M.H. and Shin, Y., 2014. Dynamic Panels with Threshold Effect and Endogeneity. London School of Economics Research Lab Working Paper Series, No: EM/2014/577. 